\title{
Estudos métricos da informação no Brasil: um campo científico exitoso
}

\section{Metric studies of information in Brazil: a successful scientific field}

\section{Estudios métricos de la información en Brasil: un campo científico}

\author{
Natanael Vitor Sobral ${ }^{1, a}$ \\ natanael.sobral@ufpe.br | https://orcid.org/0000-0003-2410-494X \\ Leilah Santiago Bufrem ${ }^{2, b}$ \\ santiagobufrem@gmail.com | https://orcid.org/0000-0002-3620-0632
}

\footnotetext{
${ }^{1}$ Universidade Federal de Pernambuco, Departamento de Ciência da Informação. Recife, PE, Brasil.

${ }^{2}$ Universidade Federal de Pernambuco, Programa de Pós-Graduação em Ciência da Informação. Recife, PE, Brasil.

a Doutorado em Ciência da Informação pela Universidade Federal da Bahia.

b Doutorado em Ciências da Comunicação pela Universidade de São Paulo.
}

Palavras-chave: Estudos métricos da informação; Comunicação científica; Informação científica em saúde; Indicadores científicos em saúde; Políticas científicas.

Keywords: Information metric studies; Scientific communication; Scientific information in health; Scientific indicators in health; Scientific policies.

Palabras clave: Estudios de métricas de información; Comunicación científica; Información científica en salud; Indicadores científicos en salud; Políticas científicas.

O desenvolvimento dos estudos métricos da informação no Brasil vem sendo um importante instrumento para a implementação e acompanhamento de políticas científicas, pois cumpre a esse campo desenvolver aportes teóricos e metodológicos para a mensuração das diversas formas de conhecimento, especialmente, os modos de produção cientificamente consagrados e institucionalizados, tais como artigos científicos, trabalhos publicados em eventos, livros, capítulos de livro e outros materiais bibliográficos.

Tal êxito se deve à tradição e organização da comunidade de cientistas brasileiros engajados no estudo das metrias informacionais, que apresenta como produto desse esforço uma série de iniciativas, como por exemplo o grupo de trabalho (GT) 7 do Encontro Nacional de Pesquisa (Enancib) da Associação de Pesquisa e Pós-graduação em Ciência da Informação (Ancib), denominado Produção e Comunicação da Informação em Ciência, Tecnologia \& Inovação (CT\&I), responsável por congregar pesquisas relacionadas aos processos de comunicação, divulgação, análise e formulação de indicadores para planejamento, avaliação e gestão em 
Reciis - Revista Eletrônica de Comunicação, Informação \& Inovação em Saúde, Rio de Janeiro, v. 16, n.1, p. 1-4, jan.-mar. 2022 [www.reciis.icict.fiocruz.br] e-ISSN 1981-6278

CT\&I (ANCIB, 2021); e pelo Encontro Brasileiro de Bibliometria e Cientometria (EBBC), evento catálogo que reúne os principais pesquisadores da área a cada dois anos.

Ao realizar uma busca de informações ${ }^{1}$ na base de dados Web of Science, uma das principais plataformas de conhecimento científico multidisciplinar, vê-se que o Brasil aparece em quinto lugar entre os países produtores de conhecimento em estudos métricos da informação científica, estando atrás apenas de China, Estados Unidos, Espanha e Inglaterra. Ao reduzir a pesquisa aos últimos cinco anos (2017 a 2021), o Brasil fica posicionado em quarto lugar, à frente da Inglaterra, consolidando-se como potência científica global do campo.

Outra evidência da relevância da comunidade científica brasileira em métricas informacionais é a produção de coletâneas, livros e dossiês que retratam o estado da arte e da técnica sobre a disciplina, proporcionando aos pares acadêmicos acesso às mais recentes discussões e inovações nesse tema. Uma iniciativa clássica, que inspirou gerações de pesquisadores e analisou um dos principais eventos da história da comunicação científica, a transição das publicações em papel para o formato eletrônico, foi o volume 2, número 27, da Revista Ciência da Informação, de Brasília. Essa histórica edição conta com o editorial de Abel Laerte Packer, Irati Antonio e Vera Sílvia Marão Beraquet, alertando para as oportunidades e desafios da inserção da comunicação científica brasileira no cenário internacional da publicação eletrônica (PACKER; ANTONIO; BERAQUET, 1998).

$\mathrm{Na}$ esteira contundente do editorial aludido, o fascículo apresenta um conjunto de artigos, fruto de uma feliz curadoria, que está presente na memória intelectual e afetiva da comunidade brasileira de estudos métricos da informação. Dentre os artigos, chamam a atenção: "Desenvolvendo indicadores estratégicos em ciência e tecnologia: as principais questões", de Edson Kenji Kondo, detentor de 58 citações no Google Scholar; "Indicadores bibliométricos e econométricos para a avaliação de instituições científicas", de Ronald Rousseau, referenciado 114 vezes; "Indicadores quantitativos: reflexões que antecedem seu estabelecimento", de Piotr Trzesniak, com 151 citações; "Indicadores cienciométricos”, de Ernesto Spinak, citado 671 vezes; e "O papel da informetria e da cienciometria e sua perspectiva nacional e internacional", de Cesar Macias-Chapula, com incríveis 1055 citações. Apesar de o número contar com outros textos do campo da comunicação científica, destacam-se aqui aqueles com enfoque métrico, sobretudo, ressaltando o impacto que causaram no desenvolvimento do campo, sendo utilizados ao longo dos anos pela comunidade científica como aporte teórico.

Passados quase 24 anos da publicação, o Brasil e o mundo encaram novos desafios, especialmente, no âmbito da saúde pública. Com a pandemia de covid-19 e a persistência de doenças infecciosas e parasitárias endêmicas, é inevitável a busca por respostas para esses problemas, o que em plano interdisciplinar implica na colaboração de diversos campos científicos, países e instituições, cada um com sua especialidade e em sua possibilidade, envolvidos em redes de pesquisa e desenvolvimento com foco em soluções (OMS, 2015).

Nesse sentido, a Revista Eletrônica de Comunicação, Informação \& Inovação em Saúde (Reciis) convocou a comunidade científica a prestar contribuições para o debate público envolvendo os estudos métricos da informação científica em saúde, a partir de dez eixos temáticos inspirados no EBBC, a saber: bases de dados e fontes de informação para a geração de indicadores de produção científica; estudos de citação e genealogia científica, acadêmica e intelectual; colaboração científica, grupos de pesquisa, mobilidade acadêmica e colégios invisíveis; indicadores bibliométricos e cientométricos sobre a produção científica; arquivometria em acervos arquivísticos; métricas sobre acesso aberto e ciência aberta; inovações metodológicas e técnicas nos estudos métricos da informação; aplicações das leis bibliométricas e cientométricas; métricas alternativas e webométricas na comunicação e avaliação da informação científica; e mapas e rankings sobre

1 Busca realizada em 23 de fevereiro de 2022, a partir do Portal de Periódicos Capes, com a expressão de busca: "bibliometric*" OR "scientometric*" OR "altmetric*" OR “informetrics". 
Reciis - Revista Eletrônica de Comunicação, Informação \& Inovação em Saúde, Rio de Janeiro, v. 16, n.1, p. 1-4, jan.-mar. 2022 [www.reciis.icict.fiocruz.br] e-ISSN 1981-6278

países, pesquisadores e instituições. Com isso, dez artigos científicos foram selecionados para publicação, integrando a edição da Reciis, ao lado de outros textos recebidos em submissão contínua pelo periódico. Cinco foram publicados na primeira parte do dossiê, apresentados em editorial específico publicado no volume 15, número 4 (SOBRAL; BUFREN, 2021), e cinco publicados na segunda parte, e apresentados nos parágrafos subsequentes deste editorial.

O primeiro artigo é intitulado "Produção científica sobre a covid-19 na ciência da informação no Brasil: uma pesquisa na Brapci”, de João Arlindo dos Santos Neto. Objetiva investigar o cenário da produção cientifica sobre a covid-19 no campo da ciência da informação. Como resultados, o estudo identifica 178 artigos publicados em periódicos científicos que tratam da temática covid-19 e apresenta 13 categorias temáticas que contemplam a diversidade de temas abordados pelos profissionais da área. A análise considera que, além do estrato Qualis dos periódicos, outros elementos foram levados em conta pelos autores no momento da escolha do veículo em que os artigos seriam publicados, como a chamada para números temáticos e dossiês especiais, e o foco e alcance de cada revista.

Em seguida, tem-se o segundo texto "Coautoria institucional na produção científica brasileira sobre hanseníase: uma análise a partir da base de dados Web of Science”, de Andréa Cristina Bogado, Fábio Sampaio Rosas e Maria Cláudia Cabrini Grácio. O estudo tem por alvo visualizar a rede de colaboração científica presente na comunidade discursiva que conduz pesquisas sobre hanseníase no Brasil, por meio das relações de coautoria institucional. As características da colaboração foram estudadas a partir da coautoria de 498 artigos indexados na base de dados Web of Science no período de 2016 a 2020. As análises revelam que parte significativa dos artigos foi publicada por um grupo reduzido de instituições e que as universidades, apesar de em maior número, possuem publicações mais pulverizadas e não ocupam a centralidade da rede, que é dominada por institutos de pesquisa.

A terceira publicação, escrita por Felipe Lopes Roberto, Matheus Hingst Tavares, Paula Carina de Araújo, Maria do Carmo Duarte Freitas e José Marcelo Almeida Prado Cestari, tem por título "A busca de informação sobre covid-19 na web: uma perspectiva cibermétrica”. Os autores objetivaram demonstrar a influência da pandemia de covid-19 nas buscas realizadas no Google, por meio do levantamento de dados em uma aplicação cibermétrica. Como principais resultados encontram-se identificação das primeiras buscas pelo termo 'covid-19' na mesma data do anúncio do primeiro caso confirmado; crescimento no volume de busca por informações sobre os sintomas de pneumonia relacionadas com a primeira morte por coronavírus; e intensificação nas consultas relativas à 'covid vaccine allergy' associada ao início da vacinação no mundo.

Adiante, tem-se o documento das autoras Bruna Lessa e Eneida Santana, "Representação da informação sobre a covid-19: rede semântica de títulos de artigos na Web of Science”, cujo propósito é representar as relações entre termos de maior relevância nas pesquisas indexadas na Web of Science sobre o novo coronavírus (SARS-CoV-2), de dezembro de 2019 a maio de 2020. Os resultados indicaram uma rede de estrutura topológica caracterizada como mundo pequeno, com uma certa quantidade de conexões similares. O termo 'covid-19' apresenta transitividade alta em grupos fortemente conectados, os quais compreendem termos de domínios do conhecimento distintos e, por vezes, pouco relacionados no contexto disciplinar da ciência. Concluiu-se que a interconexão entre termos de diferentes domínios do conhecimento forma grupos de termos emergentes, potencializando a urgência de pesquisas interdisciplinares para a compreensão do termo em destaque nesse trabalho - 'covid-19'.

Por fim, apresenta-se o artigo "Produção científica brasileira em odontologia: análise bibliométrica a partir das bases de dados Web of Science e Scopus", de Brianda Oliveira Ordonho Sigolo, Ana Paula Aparecida Calabrez, Catia Candida de Almeida e Helen de Castro Silva Casarin. Essa pesquisa objetiva analisar a produção científica da área de Odontologia, de autores afiliados ao Brasil, com registros obtidos nas duas 
principais bases de dados multidisciplinares do meio científico - Web of Science e Scopus - no período de 2010 a 2020, com o auxílio da ferramenta bibliometrix. Observaram-se nesse estudo a predominância das publicações com autoria múltipla; a maior quantidade de publicações sendo em revistas brasileiras de acesso aberto; a representatividade dos Estados Unidos como o país que mais colaborou para as pesquisas na área; e a proeminência das três universidades estaduais paulistas, no quesito quantidade de publicações.

Também em diálogo com esse campo, na seção Resenhas, Angélica Baptista Silva coloca em perspectiva o Manual de gestão arquivística de documentos em saúde, de autoria de Francisco José Aragão Pedroza Cunha, Gillian Leandro de Queiroga Lima, Louise Anunciação Fonseca de Oliveira do Amaral e Rodrigo França Meirelles - uma obra que busca sensibilizar os(as) profissionais de saúde para a adoção das tecnologias avançadas de produção, de circulação e de acesso às informações em saúde, em particular, a gestão de documentos arquivísticos e dos serviços e sistemas de arquivos.

O dossiê Estudos métricos da informação científica em saúde tem o intuito de fortalecer as perspectivas de análise do conhecimento científico para a formulação de políticas públicas, que venham a causar impacto positivo na sociedade, especificamente, com respeito ao combate às doenças e agravos presentes no território brasileiro. Ademais, espera-se neste dossiê temático fortalecer a difusão das pesquisas em estudos métricos da informação científica em saúde realizadas no Brasil, reafirmando o papel de protagonismo do país no cenário global, enaltecendo suas potencialidades, virtudes e desafios, expressando, assim, a força de uma comunidade científica que, em meio a múltiplas adversidades, insiste em resistir. Que este dossiê se some às frutíferas e plurais iniciativas de produção e disseminação da informação científica em metrias informacionais, reforçando o protagonismo do(a) cientista brasileiro(a) no mundo.

\section{REFERÊNCIAS}

ASSOCIAÇÃO DE PESQUISA E PÓS-GRADUAÇÃO EM CIÊNCIA DA INFORMAÇÃO (ANCIB).

Coordenações e Ementas de GT. GT 7 - Produção e Comunicação da Informação em Ciência, Tecnologia \& Inovação. [S. I.]: Ancib, 2021. Disponível em: https://ancib.org/coordenacoes-e-ementas-de-gt/. Acesso em: 23 fev. 2022.

ORGANIZAÇÃO MUNDIAL DA SAÚDE (OMS). The Millennium Development Goals Report: 2015. Genebra: OMS, 2015. 73 p. Disponível em: https://www.un.org/millenniumgoals/2015 MDG Report/pdf/MDG\%20 2015\%20rev\%20(July\%201).pdf. Acesso em: 01 fev. 2022.

PACKER, Abel Laerte; ANTONIO, Irati; BERAQUET, Vera Silvia Marão. Rumo à publicação eletrônica. Ciência da Informação, Brasília, DF, v. 27, n. 2, p. 1-3, 1998. DOI: https://doi.org/10.18225/ci.inf..v27i2.790. Disponível em: http://revista.ibict.br/ciinf/article/view/790. Acesso em: 24 fev. 2022.

SOBRAL, Natanael Vitor; BUFREM, Leilah Santiago. Defender a ciência é hoje um ato político decisivo.

Revista Eletrônica de Comunicação, Informação e Inovação em Saúde, Rio de Janeiro, v. 15, n. 4, p. 797800, 2021. DOI: https://doi.org/10.29397/reciis.v15i4.3141. Disponível em: https://www.reciis.icict.fiocruz.br/ index.php/reciis/article/view/3141. Acesso em: 24 fev. 2022. 